\title{
The impacts of surgery of the primary cancer and radiotherapy on the survival of patients with metastatic rectal cancer
}

\author{
Duo Tong ${ }^{1,3, *}$, Fei $\mathrm{Liu}^{2,3, *}$, Wenhua $\mathrm{Li}^{1,3, *}$ and Wen Zhang ${ }^{1,3}$ \\ ${ }^{1}$ Department of Medical Oncology, Fudan University Shanghai Cancer Center, Shanghai 200032, China \\ ${ }^{2}$ Department of Gynecological Oncology, Fudan University Shanghai Cancer Center, Shanghai 200032, China \\ ${ }^{3}$ Department of Oncology, Shanghai Medical College, Fudan University, Shanghai 200032, China \\ *These authors contributed equally to this work
}

Correspondence to: Wen Zhang, email: zw65242@163.com

Keywords: rectal cancer, surgery, radiotherapy, SEER, survival

Received: January 04, 2017 Accepted: June 28, $2017 \quad$ Published: July 11, 2017

Copyright: Tong et al. This is an open-access article distributed under the terms of the Creative Commons Attribution License 3.0 (CC BY 3.0), which permits unrestricted use, distribution, and reproduction in any medium, provided the original author and source are credited.

\section{ABSTRACT}

The role of surgery of the primary cancer and radiation in metastatic colorectal cancer ( $\mathrm{MCRC}$ ) is still controversial currently, and evidence implied that colon cancer (CC) and rectal cancer (RC) should be treated with difference. Hence we focused on metastatic rectal cancer $(\mathrm{mRC})$ solely to compare the cancer cause-specific survival (CSS) of patients receiving varied treatments of the primary cancer: no treatment, surgery only, radiation only, and surgery plus radiation, based on the records of the Surveillance, Epidemiology, and End Results (SEER) database. A total of 8669 patients were included. Results demonstrated that the 2-year CSS was $\mathbf{2 8 . 1 \%}$ for no treatment group, $\mathbf{3 0 . 7 \%}$ for only radiation group, $\mathbf{5 0 . 2 \%}$ for only surgery group, and $66.5 \%$ for surgery plus radiation group, reaching statistical difference $(P<0.001)$. Furthermore, the CSSs of $\mathrm{mRC}$ patients in the surgery group were similar regardless of resection ranges $(P=0.44)$. Besides, we analyzed the prognostic factors for $\mathrm{mRC}$ and found carcinoembryonic antigen (CEA) level, metastasis (M) stage, Tumor ( $T$ ) stage, tumor size, differentiate grade, age and marital status should be taken into consideration when estimating the prognosis. Particularly, patients with normal CEA level or M1a stage showed a significant survival advantage. Overall, present study suggested that surgery of the primary cancer and radiation might help to improve the survival of $\mathrm{mRC}$ patients, especially when both treatments were conducted. Our results may assist clinicians to make better treatment strategy for patients with $\mathrm{mRC}$.

\section{INTRODUCTION}

Colorectal cancer (CRC) is one of the most frequently diagnosed cancers worldwide, ranking the second leading cause of cancer-related death in the United States [1, 2]. In China, CRC is also among the five most common cancers and is the fifth leading cause of cancer-related death in both sexes [3]. Over half of CRC patients will develop metastases [4-6], and the 5-year relative survival rate of metastatic colorectal cancer (mCRC) is merely $10 \%$ [7]. So it is urgent to improve the survival of mCRC patients. Although commonly referred as $\mathrm{CRC}$, colon cancer (CC) and rectal cancer (RC) differ in embryological origin, anatomical features and molecular pathologic traits, leading to distinct clinical characteristics $[8,9]$. Considering the differences between $\mathrm{CC}$ and $\mathrm{RC}$, and the fact that $\mathrm{RC}$ is more prevalent in China, we focus on metastatic rectal cancer (mRC) solely in this study [10].

For decades, great progress has been achieved in the field of the treatment of mRC. The utilization of several cytotoxic drugs [11-13]and targeted drugs [14, 15] has greatly improved the prognosis of patients. However, the 5-year relative survival rate of $\mathrm{mRC}$ still remains unsatisfactory. Chemotherapy is currently the primary treatment of $\mathrm{mRC}$, while previous studies in RC implied that surgery of the primary cancer or radiotherapy might also play a positive role in the control of metastatic disease $[16,17]$. The NCCN guidelines stratify mRC 
patients based on their status of metastases and include surgery and/or radiotherapy as potential treatment options for different groups. Recent studies found that varied treatment options of the primary cancer might exert different effects on the survival of gastrointestinal cancer patients $[18,19]$. However, similar study in a large population focusing on $\mathrm{mRC}$ solely is currently scarce.

Moreover, traditional TNM ( $\mathrm{T}$, tumor; N, lymph node; $\mathrm{M}$, metastasis) staging system is commonly used to guide the treatment and predict the prognosis of patients with RC. While for patients with mRC, some show worse survival than the others in spite of the same TNM stage. So extra prognostic factors may exist to help predict the outcome and tailor the treatment more precisely for $\mathrm{mRC}$ patients. According to the reports, some demographic and clinicopathological factors have already been found to be associated with the survival of gastrointestinal cancer patients [20-23]. Here we also intended to explore potential prognostic factors for $\mathrm{mRC}$ patients within the scope of demographic and clinicopathological factors.

So we conducted this study in $\mathrm{mRC}$ to investigate the relationship between cancer cause-specific survival (CSS) and the treatment options of primary cancer, as well as to find the demographic and clinicopathological prognostic factors, based on the Surveillance, Epidemiology, and End Results (SEER) database.

\section{RESULTS}

\section{Patient baseline characteristics}

We identified $8669 \mathrm{mRC}$ patients in total for analysis from January 2004 to December 2013 based on the SEER database. Patients' baseline demographics and clinicopathological characteristics were displayed in Table 1. 5385(62.1\%) males and 3284(37.9\%) females were included, mainly Caucasian (79\%). The average age of patients was 61.2 years.

\section{Analysis of the impacts of demographic and clinicopathologic characteristics on $\mathrm{mRC}$ patients' CSS}

As summarized in Table 2, no surgery of primary cancer $(P<0.001)$, no radiation $(P<0.001)$, M1b stage $(P<0.001)$, elevated CEA level $(P<0.001)$, older age $(P<0.001)$, unmarried status $(P<0.001)$, signet ring cell carcinoma $(P<0.001)$, undifferentiated grade $(P<0.001)$, larger tumor size $(P<0.001)$ and T1/4 stage $(P<0.001)$ were found to be risk factors for $\mathrm{mRC}$ patients' survival by univariate log-rank test. All these factors were then identified as independent prognostic factors by multivariate Cox regression. Notably, the 2-year CSSs for T2 stage and T3 stage were $55.5 \%$ and $52.4 \%$ respectively, while the rates were $37.6 \%$ and $33.0 \%$ for T1 stage and T4 stage $(P<0.001)$ (Table 2 and Figure 5), suggesting the survival of patients with T2/T3 stage was better than that of patients with T1/T4 stage in mRC. Among the prognostic factors identified, surgery of the primary cancer and radiation were included, which we planed to study further.

\section{Analysis of the impacts of surgery of the primary cancer on $\mathrm{mRC}$ patients' CSS}

In the cohort of analysis, among the $8629(99.5 \%)$ patients with known information of surgery, 3247(37.6\%) patients have performed surgery of the primary cancer. The 2-year CSS was $58.7 \%$ for patients who performed the surgery, while the rate was merely $29.3 \%$ for those who didn't, reaching statistical significance by both univariate log-rank test and multivariate Cox regression analyses $(P<0.001)$ (Figure 1A and Table 2). We then analyzed the demographic and tumor characteristics in the two groups. Results demonstrated that patients in the surgery group were younger $(P<0.001)$, more married $(P<0.001)$, more with T3 stage $(P<0.001)$, more with smaller tumor size $(P<0.001)$, more with normal CEA level $(P<0.001)$ and more treated with radiotherapy $(P<0.001)$. The result implied that patients in the surgery group possessed more favorable survival factors.

As records in the SEER database also include the resection range of surgery, we further studied the prognostic differences within the surgery group according to the resection range. 3159 patients with known information of resection range were included for this analysis and they were divided into four groups based on the record. The result indicated that resection range did not affect the CSS of mRC patients $(P=0.44)$ (Figure 1B). It seemed that as long as the primary tumors were removed, mRC patients' prognoses would be similar regardless of varied resection ranges.

\section{Analysis of the impacts of radiation on $\mathrm{mRC}$ patients' CSS}

Of the whole cohort, $8536(98.5 \%) \mathrm{mRC}$ patients owned known information of radiotherapy and among them 3662 (42.9\%) have received radiation. The 2-year CSS was $47.4 \%$ for patients who received radiation, compared with $36.0 \%$ for those who did not, reaching statistical difference by both univariate and multivariate analyses $(P<0.001)$ (Figure 2 and Table 2$)$.

Considering the combination of surgery of the primary cancer and radiation may achieve better survival as reported in local advanced disease [19], we then conducted survival analysis according to varied treatment combinations in $\mathrm{mRC}$. The survival curves showed the 2-year CSS was $28.1 \%$ for no treatment group, 30.7\% for only radiation group, $50.2 \%$ for only surgery group, and $66.5 \%$ for surgery plus radiation group, reaching statistical difference $(P<0.001)$ (Figure 3$)$. It displayed that surgery of the primary cancer or radiation could improve patients' 
Table 1: Baseline demographic and clinicopathological characteristics of $\mathrm{mRC}$ patients in the SEER database (2004-2013)

\begin{tabular}{|c|c|}
\hline Characteristics & $N(\%)($ Total $N=8669)$ \\
\hline \multicolumn{2}{|l|}{ Gender } \\
\hline Male & $5385(62.1)$ \\
\hline Female & $3284(37.9)$ \\
\hline \multicolumn{2}{|l|}{ Age at diagnosis (year) } \\
\hline$<60$ & $4059(46.8)$ \\
\hline$\geq 60$ & $4610(53.2)$ \\
\hline Mean \pm SD & $61.2 \pm 13.7$ (years) \\
\hline \multicolumn{2}{|l|}{ Year of diagnosis } \\
\hline 2004-2009 & $4973(57.4)$ \\
\hline 2010-2013 & $3696(42.6)$ \\
\hline \multicolumn{2}{|l|}{ Ethnicity } \\
\hline Caucasian & $6852(79.0)$ \\
\hline Non-Caucasian & $1794(20.7)$ \\
\hline Unknown & $23(0.3)$ \\
\hline \multicolumn{2}{|l|}{ Marital status } \\
\hline Married & $4322(49.9)$ \\
\hline Unmarried & $3987(46)$ \\
\hline Unknown & $360(4.1)$ \\
\hline \multicolumn{2}{|l|}{ Histology } \\
\hline Adenocarcinoma & $8136(93.9)$ \\
\hline Mucinous adenocarcinoma & $385(4.4)$ \\
\hline Signet ring cell carcinoma & $148(1.7)$ \\
\hline \multicolumn{2}{|l|}{ Grade } \\
\hline Well & $392(4.5)$ \\
\hline Moderate & $4861(56.1)$ \\
\hline Poor & $1513(17.5)$ \\
\hline Undifferentiated & $109(1.3)$ \\
\hline Unknown & $1794(20.7)$ \\
\hline \multicolumn{2}{|l|}{$T$ stage } \\
\hline $\mathrm{T} 1$ & $1127(13.0)$ \\
\hline $\mathrm{T} 2$ & $300(3.5)$ \\
\hline $\mathrm{T} 3$ & $3353(38.7)$ \\
\hline $\mathrm{T} 4$ & $1488(17.2)$ \\
\hline $\mathrm{Tx}$ & $2401(27.7)$ \\
\hline \multicolumn{2}{|l|}{$N$ stage } \\
\hline No & $2887(33.3)$ \\
\hline N1 & $2677(30.9)$ \\
\hline N2 & $1582(18.2)$ \\
\hline $\mathrm{Nx}$ & $1523(17.6)$ \\
\hline \multicolumn{2}{|l|}{ M status } \\
\hline M1a & $2176(25.1)$ \\
\hline M1b & $6208(72.6)$ \\
\hline M1x & $286(3.3)$ \\
\hline \multicolumn{2}{|l|}{ Tumor size } \\
\hline $0-4 \mathrm{~cm}$ & $1686(19.4)$ \\
\hline $4-8 \mathrm{~cm}$ & $2567(29.5)$ \\
\hline$>8 \mathrm{~cm}$ & $141(1.6)$ \\
\hline Unknown & $4305(49.5)$ \\
\hline \multicolumn{2}{|l|}{ CEA } \\
\hline Normal & $977(11.3)$ \\
\hline Elevated & $4927(56.8)$ \\
\hline Unknown & $2765(31.9)$ \\
\hline
\end{tabular}




\begin{tabular}{lc} 
Surgery & \\
No & $5382(62.1)$ \\
Yes & $3247(37.4)$ \\
1.Local tumor excision & $356(4.0)$ \\
2.Partial proctectomy & $2025(23.4)$ \\
3.Total proctectomy or proctocolectomy & $678(7.8)$ \\
4.Total proctectomy with an en bloc resection of other organs & $100(1.2)$ \\
5.Unknown resection range & $88(1.0)$ \\
Unknown & $40(0.5)$ \\
Radiation & \\
No & $4874(56.2)$ \\
Yes & $3662(42.2)$ \\
1.Beam radiation & $3557(41.0)$ \\
2.Radioactive implants & $10(0.1)$ \\
3.Combination of beam with implants or isotopes & $6(0.06)$ \\
4. Radioisotopes & $4(0.04)$ \\
5.Radiation, NOS & $85(1.0)$ \\
Unknown & $133(1.5)$ \\
\hline
\end{tabular}

Abbreviations: mRC, metastatic rectal cancer; $N$, number of patients; SD, standard deviation; $T$, tumor; $N$ stage, lymph node stage; M, metastasis; M1x, metastasis without exact M stage; CEA, carcinoembryonic antigen; NOS, not otherwise specified.

survival and patients with combined treatments benefited the most in mRC. Additionally, the survival of patients who received surgery only was better than that of those who received only radiation, implying surgery of the primary cancer may potentially take better control of the disease. The conclusion was also verified by multivariate analysis (Table 2).

We next analyzed the characteristics differed in the four groups receiving varied treatments of the primary cancer: 1.SURG-RAD-, neither treatments; $2 . \mathrm{SURG}^{-}$ RAD+, only radiation; 3.SURG+RAD-, only surgery; 4.SURG+RAD+, both treatments. The data showed that age, year of diagnosis, marital status, histological type, tumor size, $T$ stage, $N$ stage, $M$ stage and CEA level differed in these groups, reaching statistical differences. Moreover, the percentage of patients with normal CEA level or with M1a stage in the "SURG+RAD+" group was significantly higher than that of the other three groups. Hence we selected CEA level and M stage for further study.

\section{Analysis of the influence of CEA level and M stage on mRC patients' CSS based on surgery and/or radiation status}

Univariate analysis demonstrated that patients with normal CEA level $(P<0.001)$ or with M1a stage had better CSS $(P<0.001)$, with statistical difference. The result of multivariate analysis was in correspondence with that of univariate analysis (Table 2).

After stratified by primary surgery status, we observed normal CEA level as well as M1a stage held a survival advantage in both surgery group and non-surgery group $(P$ $<0.001, P<0.001)$. While the survival curves showed the CSS of mRC patients was still mainly determined by the status of primary surgery regardless of CEA level or M stage $(P<0.001, P<0.001)$ (Figure 4A and 4B).

Additionally, as shown in Figure 4C and 4D, we studied the influence of CEA level and M stage on the survival of $\mathrm{mRC}$ patients according to radiation status. The results demonstrated that normal CEA level and M1a stage still maintained their survival advantage after stratified by radiation status $(P<0.001, P<0.001)$. However, unlike the analysis based on surgery status, the survival of group $\mathrm{RAD}+\mathrm{M} 1 \mathrm{~b}$ (with radiation and with M1b stage) was worse than that of group RAD-M1a (without radiation and with M1a stage) $(P<0.05)$.

Moreover, we compared the survival differences in groups divided by both surgery and radiation status (SURG-RAD-, SURG-RAD+, SURG+RAD-, and SURG+RAD+) according to CEA level or $M$ stage. Both univariate log-rank test and multivariate Cox regression analyses were conducted. The result implied that normal CEA level and M1 a stage still predicted better prognosis after stratified by both surgery and radiation status in mRC. While the statistical significance for M1a stage was observed in all groups except for group SURG-RAD- (without surgery and without radiation), implying the survival advantage of M1a stage could not be demonstrated in the absence of treatment for primary cancer. So probably a more aggressive approach should be taken to treat the primary cancer for $\mathrm{mRC}$ patients with M1a stage (Table 3).

Conclusively, we found the prognosis of $\mathrm{mRC}$ patients who underwent surgery of the primary cancer or received radiotherapy was better than that of those who didn't, and combined treatments contributed to the best survival. Besides, normal CEA level and M1a stage predicted better prognosis for $\mathrm{mRC}$ patients. Hence 
Table 2: Analysis of the effects of demographic and clinicopathological characteristics on cancer cause-specific survival of $\mathrm{mRC}$ patients in the SEER database

\begin{tabular}{|c|c|c|c|c|c|}
\hline \multirow{2}{*}{ Variable } & \multirow{2}{*}{ 2-year CSS } & \multicolumn{2}{|c|}{ Univariate analysis } & \multicolumn{2}{|c|}{ Multivariate analysis } \\
\hline & & Log rank $\chi^{2}$ & $P^{a}$ & HR $(95 \%$ CI) & $P^{b}$ \\
\hline Gender & & 2.488 & 0.115 & & \\
\hline $\begin{array}{l}\text { Female } \\
\text { Male }\end{array}$ & $\begin{array}{l}42.2 \% \\
39.6 \%\end{array}$ & & & $\begin{array}{c}0.899(0.770-1.049) \\
\text { Reference }\end{array}$ & 0.746 \\
\hline Age at diagnosis & & 230.1 & $<0.001$ & & \\
\hline $\begin{array}{l}<60 \\
\geq 60\end{array}$ & $\begin{array}{l}49.6 \% \\
33.3 \%\end{array}$ & & & $\begin{array}{c}0.682(0.615-0.757) \\
\text { Reference }\end{array}$ & $<0.001$ \\
\hline Year of diagnosis & & 23.7 & $<0.001$ & & \\
\hline $\begin{array}{l}2004-2009 \\
2010-2013\end{array}$ & $\begin{array}{l}39.7 \% \\
45.1 \%\end{array}$ & & & $\begin{array}{c}1.117(0.581-2.149) \\
\text { Reference }\end{array}$ & 0.214 \\
\hline Ethnicity & & 5.057 & 0.025 & & \\
\hline $\begin{array}{l}\text { Caucasian } \\
\text { Non-Caucasian }\end{array}$ & $\begin{array}{l}41.9 \% \\
38.7 \%\end{array}$ & & & $\begin{array}{c}1.025(0.865-1.214) \\
\text { Reference }\end{array}$ & 0.251 \\
\hline Marital status & & 116.0 & $<0.001$ & & \\
\hline $\begin{array}{l}\text { Married } \\
\text { Unmarried }\end{array}$ & $\begin{array}{l}46.2 \% \\
35.2 \%\end{array}$ & & & $\begin{array}{c}0.849(0.763-0.944) \\
\text { Reference }\end{array}$ & 0.003 \\
\hline Histology & & 78.9 & $<0.001$ & & \\
\hline $\begin{array}{l}\text { Adenocarcinoma } \\
\text { Mucinous } \\
\text { Signet ring cell }\end{array}$ & $\begin{array}{l}41.9 \% \\
39.1 \% \\
10.4 \%\end{array}$ & & & $\begin{array}{c}0.550(0.379-0.797) \\
0.620(0.404-0.950) \\
\text { Reference }\end{array}$ & $\begin{array}{l}0.002 \\
0.028\end{array}$ \\
\hline Grade & & 128.1 & $<0.001$ & & \\
\hline $\begin{array}{l}\text { Well } \\
\text { Moderate } \\
\text { Poor } \\
\text { Undifferentiated }\end{array}$ & $\begin{array}{l}45.9 \% \\
47.4 \% \\
31.2 \% \\
27.7 \%\end{array}$ & & & $\begin{array}{c}0.527(0.332-0.834) \\
0.475(0.320-0.706) \\
0.759(0.506-1.139) \\
\text { Reference }\end{array}$ & $\begin{array}{c}\mathbf{0 . 0 0 6} \\
<\mathbf{0 . 0 0 1} \\
0.183\end{array}$ \\
\hline$T$ stage & & 198.5 & $<0.001$ & & \\
\hline $\begin{array}{l}\mathrm{T} 1 \\
\mathrm{~T} 2 \\
\mathrm{~T} 3 \\
\mathrm{~T} 4\end{array}$ & $\begin{array}{l}37.6 \% \\
55.5 \% \\
52.4 \% \\
33.0 \%\end{array}$ & & & $\begin{array}{c}0.703(0.713-1.068) \\
0.443(0.464-0.820) \\
0.657(0.591-0.762) \\
\text { Reference }\end{array}$ & $\begin{array}{c}0.187 \\
\mathbf{0 . 0 0 1} \\
<\mathbf{0 . 0 0 1}\end{array}$ \\
\hline$N$ stage & & 20.9 & $<0.001$ & & \\
\hline $\begin{array}{l}\text { N0 } \\
\text { N1 } \\
\text { N2 }\end{array}$ & $\begin{array}{l}41.0 \% \\
46.7 \% \\
47.3 \%\end{array}$ & & & $\begin{array}{c}1.049(0.900-1.222) \\
1.026(0.901-1.168) \\
\text { Reference }\end{array}$ & $\begin{array}{l}0.541 \\
0.700\end{array}$ \\
\hline$M$ stage & & 195.6 & $<0.001$ & & \\
\hline $\begin{array}{l}\text { M1a } \\
\text { M1b }\end{array}$ & $\begin{array}{l}55.8 \% \\
37.0 \%\end{array}$ & & & $\begin{array}{c}0.708(0.607-0.826) \\
\text { Reference }\end{array}$ & $<0.001$ \\
\hline Tumor size & & 49.31 & $<0.001$ & & \\
\hline $\begin{array}{l}0-4 \mathrm{~cm} \\
4-8 \mathrm{~cm} \\
>8 \mathrm{~cm}\end{array}$ & $\begin{array}{l}50.7 \% \\
46.8 \% \\
36.6 \%\end{array}$ & & & $\begin{array}{c}0.694(0.588-0.817) \\
1.005(0.867-1.164) \\
\text { Reference }\end{array}$ & $\begin{array}{c}<\mathbf{0 . 0 0 1} \\
0.951\end{array}$ \\
\hline CEA & & 124.7 & $<0.001$ & & \\
\hline $\begin{array}{l}\text { Normal } \\
\text { Elevated }\end{array}$ & $\begin{array}{l}56.4 \% \\
38.4 \%\end{array}$ & & & $\begin{array}{c}0.674(0.589-0.771) \\
\text { Reference }\end{array}$ & $<0.001$ \\
\hline Surgery & & 804.1 & $<0.001$ & & \\
\hline $\begin{array}{l}\text { No } \\
\text { Yes }\end{array}$ & $\begin{array}{l}29.3 \% \\
58.7 \%\end{array}$ & & & $\begin{array}{c}2.331(2.062-2.635) \\
\text { Reference }\end{array}$ & $<0.001$ \\
\hline
\end{tabular}




\begin{tabular}{|c|c|c|c|c|c|}
\hline Radiation & & 202.1 & $<0.001$ & & \\
\hline No & $36.0 \%$ & & & $1.294(1.162-1.440)$ & $<0,001$ \\
\hline Yes & $47.4 \%$ & & & Reference & $<0.001$ \\
\hline Surgery + Radiation & & 923.9 & $<0.001$ & & \\
\hline $\mathrm{No}+\mathrm{No}$ & $28.1 \%$ & & & $3.097(2.612-3.673)$ & $<0.001$ \\
\hline No +Yes & $30.7 \%$ & & & $2.560(2.181-3.005)$ & $<0.001$ \\
\hline Yes + No & $50.2 \%$ & & & $1.41(1.235-1.610)$ & $<0.001$ \\
\hline Yes +Yes & $66.5 \%$ & & & Reference & \\
\hline
\end{tabular}

$P^{a}: P$ value for comparisons between groups by log-rank test.

$P^{b}: P$ value for comparisons between groups by multivariable Cox regression analysis adjusting for covariates.

Abbreviations: $\mathrm{mRC}$, metastatic rectal cancer; CSS, cancer cause-specific survival; HR, hazard ratio; CI, confidence interval; T, tumor; N, lymph node; M, metastasis; CEA, carcinoembryonic antigen.

clinicians may estimate the prognosis of mRC patients by checking their information of surgery of the primary cancer first, and then take radiotherapy, CEA level and
M stage records into consideration. Overall, our results supported the addition of surgery of the primary cancer and radiation into the treatment strategy of $\mathrm{mRC}$ patients.
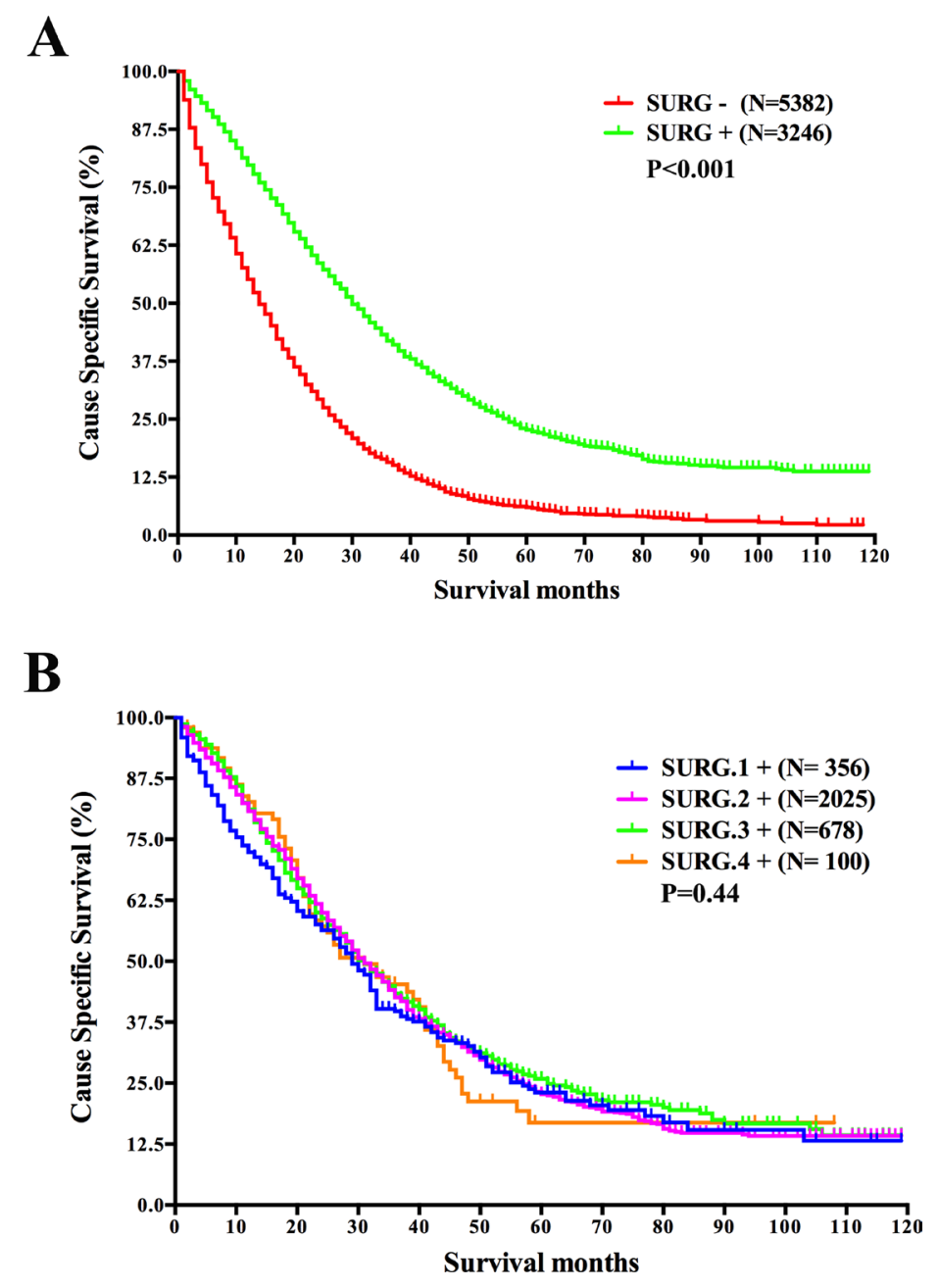

Figure 1: Survival analysis based on the status of surgery of the primary cancer and survival analysis based on surgical resection range in $\mathbf{m R C}$. (A) Survival analysis based on the status of surgery of the primary cancer. (B) Survival analysis based on surgical resection range in patients with surgery of the primary cancer. Abbreviations: $N$, number of patients; SURG-, without surgery of the primary cancer; SURG+, with surgery of the primary cancer; SURG.1+, the excision of local tumor; SURG.2+, partial proctectomy; SURG.3+, total proctectomy or total proctocolectomy; SURG.4+, total proctectomy or proctocolectomy with an en bloc resection of other organs, including pelvic exenteration. 


\section{DISCUSSION}

More than half of newly diagnosed CRC in China is RC, and a considerable part of RC has already developed metastasis at diagnosis [24]. Therefore, it's necessary to find proper therapeutic combinations and prognostic factors for $\mathrm{mRC}$ patients to help make better multidisciplinary treatment and follow-up plan. Hence we conducted this analysis to find potential prognostic factors for mRC patients based on the SEER database. We discovered that patients who performed surgery of the primary cancer or received radiation had better prognosis than those who didn't in mRC. Besides, patients with normal CEA level or M1a stage maintained a survival advantage. Nevertheless, to our attention, the CSS of patients with $\mathrm{T} 1$ stage was similar to that of patients with $\mathrm{T} 4$ stage, being worse than that of patients with $\mathrm{T} 2 / 3$ stage. Moreover, we observed that patients presenting better survival were younger, more married, with smaller tumor size and with better differentiate grade, in correspondence with results of previous analyses [25-27].

For $\mathrm{mRC}$ patients with resectable primary cancer and resectable liver or lung metastasis, the NCCN guidelines recommend the resection of both primary and

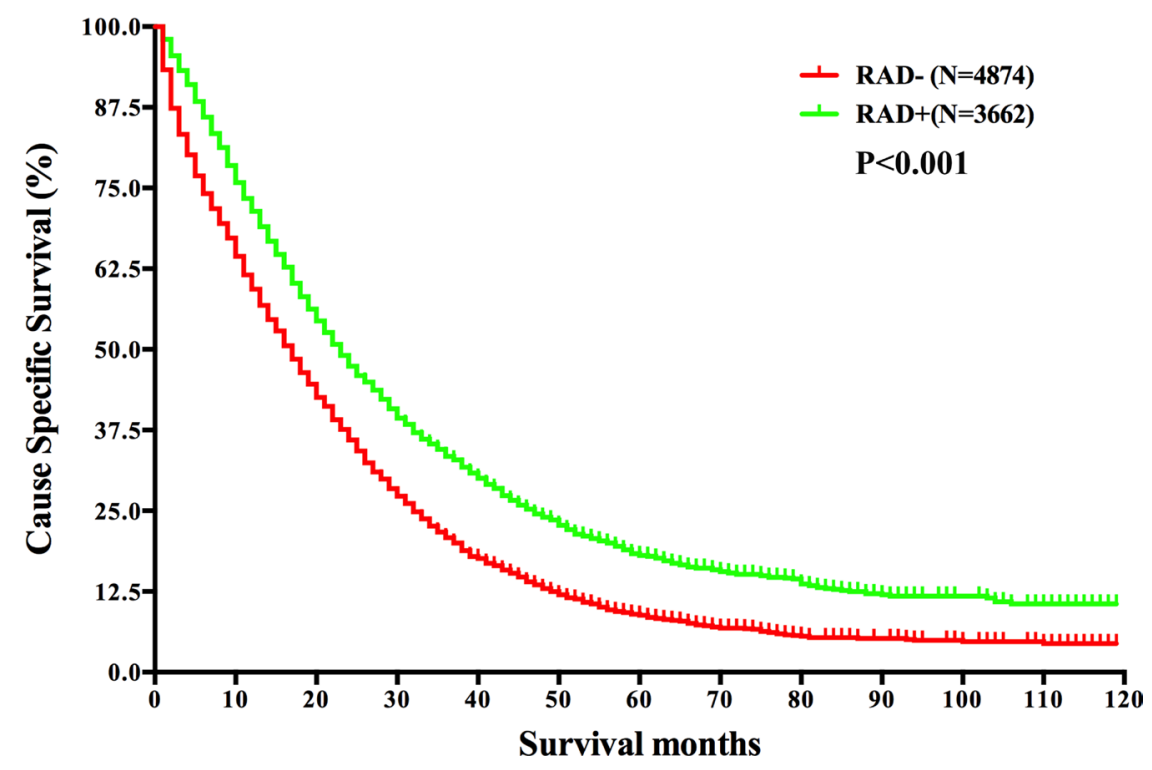

Figure 2: Survival analysis based on the status of radiation in mRC. Abbreviations: $N$, number of patients; RAD-, without radiation; $\mathrm{RAD}+$, with radiation.

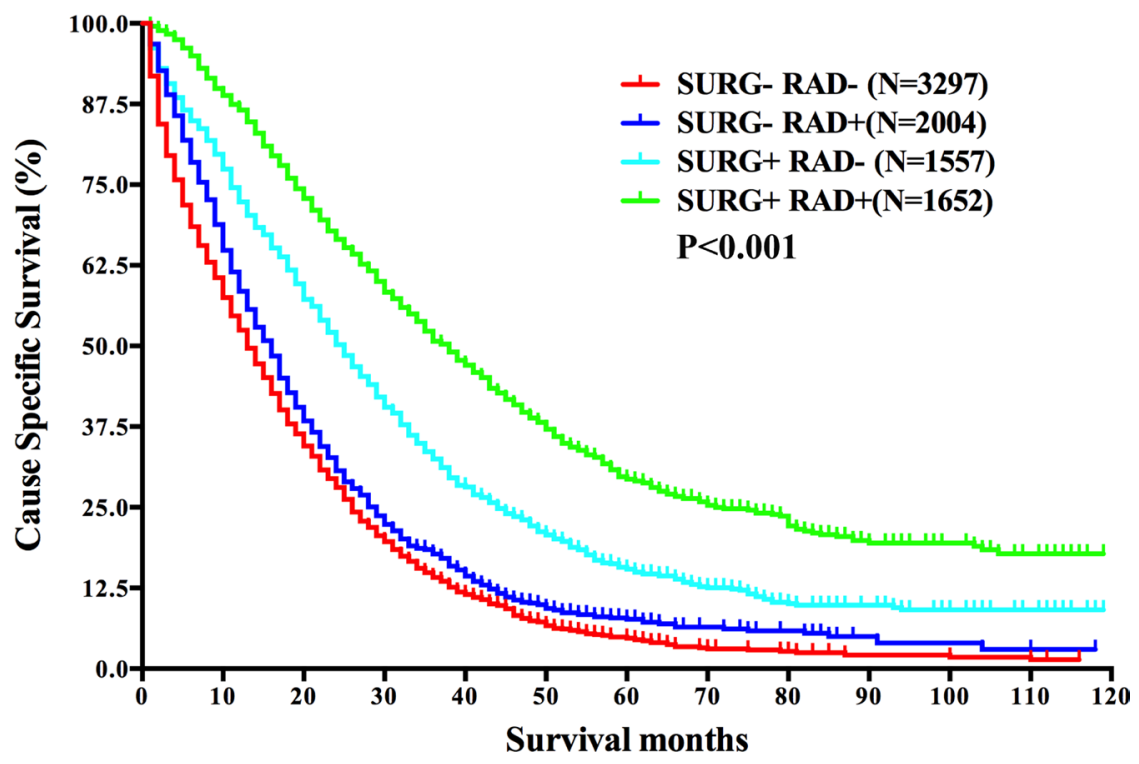

Figure 3: Survival analysis based on the status of both surgery and radiation in mRC. Abbreviations: $N$, number of patients; SURG-, without surgery of the primary cancer; SURG+, with surgery of the primary cancer; RAD-, without radiation; RAD+, with radiation. 
metastatic site to achieve the goal of cure. While for mRC with unresectable metastases presenting no symptoms (bleeding, obstruction and perforation), the resection of primary site is controversial. Part of studies claimed the resection of primary cancer may confer a survival benefit for mCRC patients with unresectable metastases and questioned the rational of undergoing primary surgery based solely on the presence of symptoms [16, 28-31], while other studies denied the survival differences between surgery group and non-surgery group [32, 33]. Considering the inconsistent results and the small size of these studies, as well as the existence of selection bias, it's difficult for us to reach a consensus.

Our analysis was based on the records of the SEER database, which includes about a quarter of the whole population of the USA. In correspondence with the study based on Norwegian Rectal Cancer Registry database [34], we found the 2-year CSS was $58.7 \%$ for patients

A

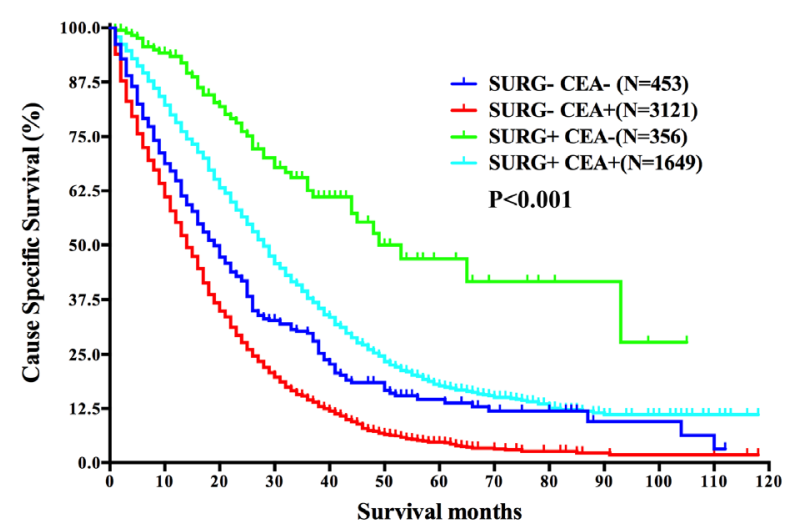

B

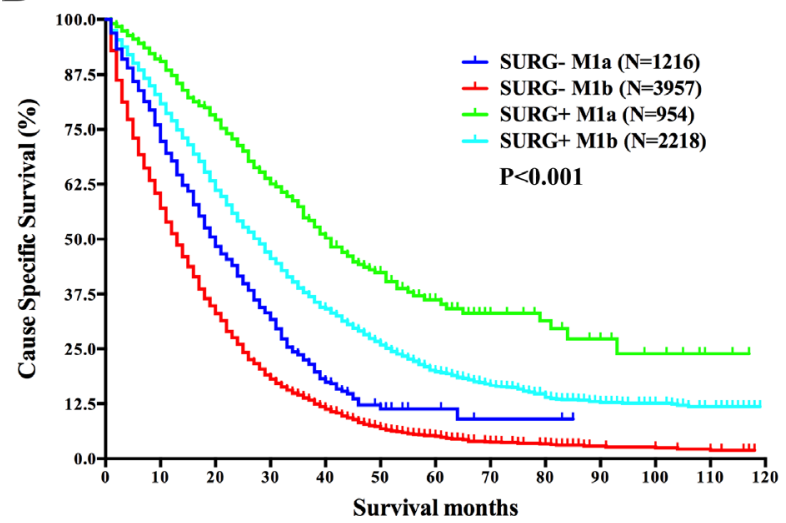

who performed primary surgery, compared with $29.3 \%$ for those who didn't in $\mathrm{mRC}$. As records in the SEER database include the code of surgical resection range, we further analyzed the influence of surgical resection range on the CSS of mRC patients. Noteworthily, it demonstrated that as long as the primary tumors were resected, the CSSs of patients would be similar regardless of varied resection ranges. In addition, the analysis between surgery group and non-surgery group showed that patients who performed the surgery tended to be younger, with smaller tumor size, with smaller metastatic burden (M1a stage) and with normal CEA level, which was in consistent with some former studies $[35,36]$. Besides, in the surgery group more patients received radiotherapy compared with non-surgery group. Considering the result of the analysis of prognostic factors above, it is not hard to find that the surgery group possessed more favorable prognostic factors, which might contribute to the survival advantage to some extent.

$\mathrm{C}$

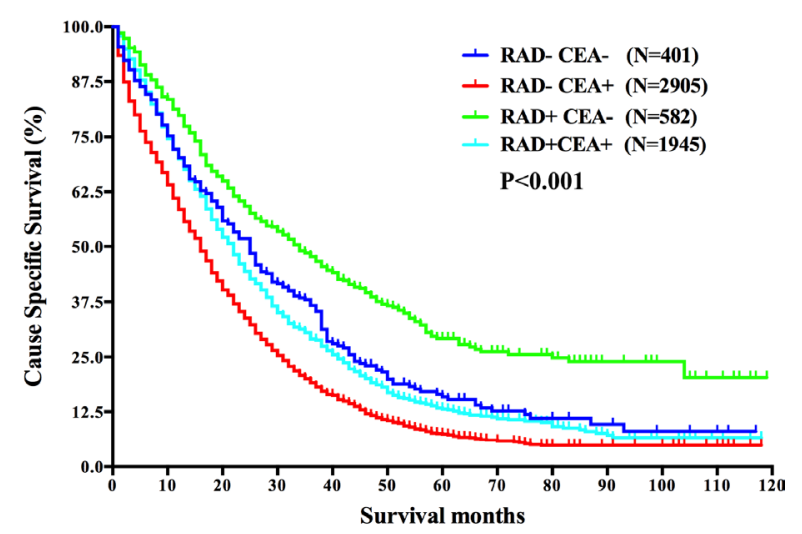

D

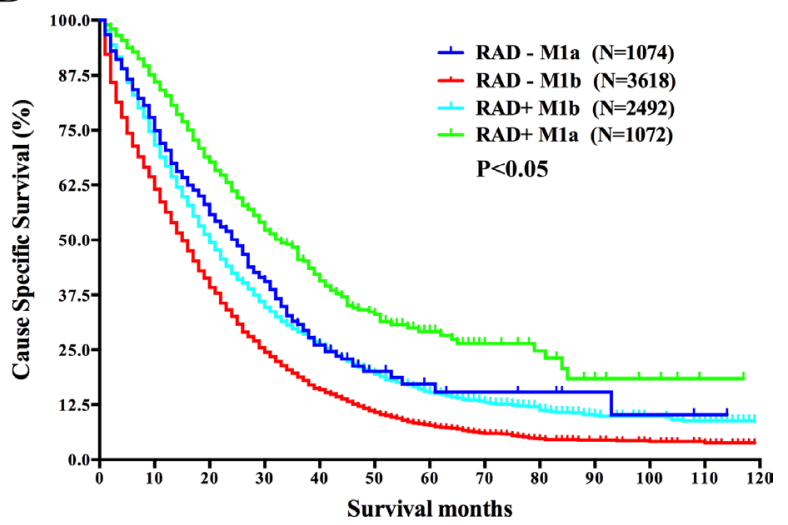

Figure 4: Survival analysis in different subgroups divided by surgery of the primary cancer or radiation and CEA level or $\boldsymbol{M}$ stage in $\mathbf{m R C}$. (A) Survival differences between subgroups divided by surgery and CEA level. (B) Survival differences between subgroups divided by surgery and M stage. (C) Survival differences between subgroups divided by radiation and CEA level. (D) Survival differences between subgroups divided by radiation and $M$ stage. Abbreviations: $N$, number of patients; SURG-, without surgery of the primary cancer; SURG+, with surgery of the primary cancer; RAD-, without radiation; RAD+, with radiation; CEA-, with normal CEA level; CEA+, with elevated CEA level; M1a, M1a stage, metastasis confined to one organ/site; M1b, M1b stage, metastases to more than one organs/sites or peritoneum. 
Moreover, we found the introduction of radiotherapy into treatment strategy improved the CSS of $\mathrm{mRC}$ patients. A few studies have been conducted previously attempting to clarify the role of radiation in $\mathrm{mRC}$. However, the results were not solid for small cohorts and varied use of chemotherapy, not to mention the conflicting results $[29,37,38]$. While our study was based on a largescale population, making the result more reliable. Notably, the patients who received both surgery and radiation modalities showed the best CSS $(66.5 \%)$, compared with "only surgery" (50.2\%), "only radiation" (30.7\%) and "no surgery no radiation" (28.1\%) groups. Previously, Wan JF et al. have drawn a similar conclusion in local advanced RC patients with older age [19], and in our case the result still made sense for $\mathrm{mRC}$ patients of all ages on the base of a large population cohort.

In addition, our results showed that $\mathrm{mRC}$ patients with normal CEA level or M1a stage presented better survival in both surgery group and non-surgery group. Further, we analyzed the prognostic significance of CEA level and $\mathrm{M}$ stage in subgroups divided by both surgery and radiation status. The results demonstrated that normal CEA level or M1a stage still held a survival advantage in these subgroups, all reaching statistical significance except for M1a stage in "no surgery no radiation" subgroup.

CEA is an important tumor marker in CRC and the influence of CEA level on CRC has long been studied. Preoperative high CEA levels were showed to be associated with high rates of postoperative recurrence and metastass in varied stage of CRC [39-42]. So it's recommended to monitor the CEA level routinely during followup [43]. In unresectable mCRC, elevated CEA levels were commonly considered to be associated with worse survival, but the conclusion is also controversial $[44,45]$. Few studies focused on the effects of CEA level on RC solely. Tarantino I et al. and Giessen C et al. demonstrated that the survival of patients with elevated preoperative CEA levels is worse than that of patients with normal CEA level in non-metastatic RC [46, 47], while the study didn't include $\mathrm{mRC}$ patients in analysis. Most researches studied the role of CEA in locally advanced RC with neoadjuvant treatment [48], however, few studies focused on mRC. And our study analyzed the relationship between CEA level and the prognosis of $\mathrm{mRC}$ patients on the base of a large population cohort. The analysis demonstrated that normal CEA level predicted better survival in $\mathrm{mRC}$, and the conclusion still made sense after stratified by surgery and/or radiation status.

Metastatic disease is classified as M1a when metastases are confined to only one site/organ in $\mathrm{mRC}$, and M1b stage is used for metastases to multiple distant sites/organs or peritoneum. Our analysis observed patients with M1a stage had better survival than patients with M1b stage, implying larger metastatic loads exerted bad effects on the prognosis of $\mathrm{mRC}$ patients. The result here identified the survival differences existed in groups with varied metastatic burden $[49,50]$. The survival benefit of M1a stage maintained in subgroups with different treatments of primary cancer except for group "no surgery no radiation", indicating the survival advantage of smaller metastatic burden could not be displayed unless some treatments of the primary cancer have been conducted. So probably a more aggressive treatment strategy should be taken to treat the primary cancer for $\mathrm{mRC}$ patients with M1a stage.

The impacts of $\mathrm{T}$ stage on the survival of local advanced RC has been learned in prior studies, stating the prognosis of patients with $\mathrm{T} 1$ or $\mathrm{T} 2$ stage is better than that of patients with T3 or T4 stage [51, 52], but analysis of the effects of $\mathrm{T}$ stage on $\mathrm{mRC}$ is quite rare. Our study noticed the CSS of patients with $\mathrm{T} 2$ or T3 stage was better than that

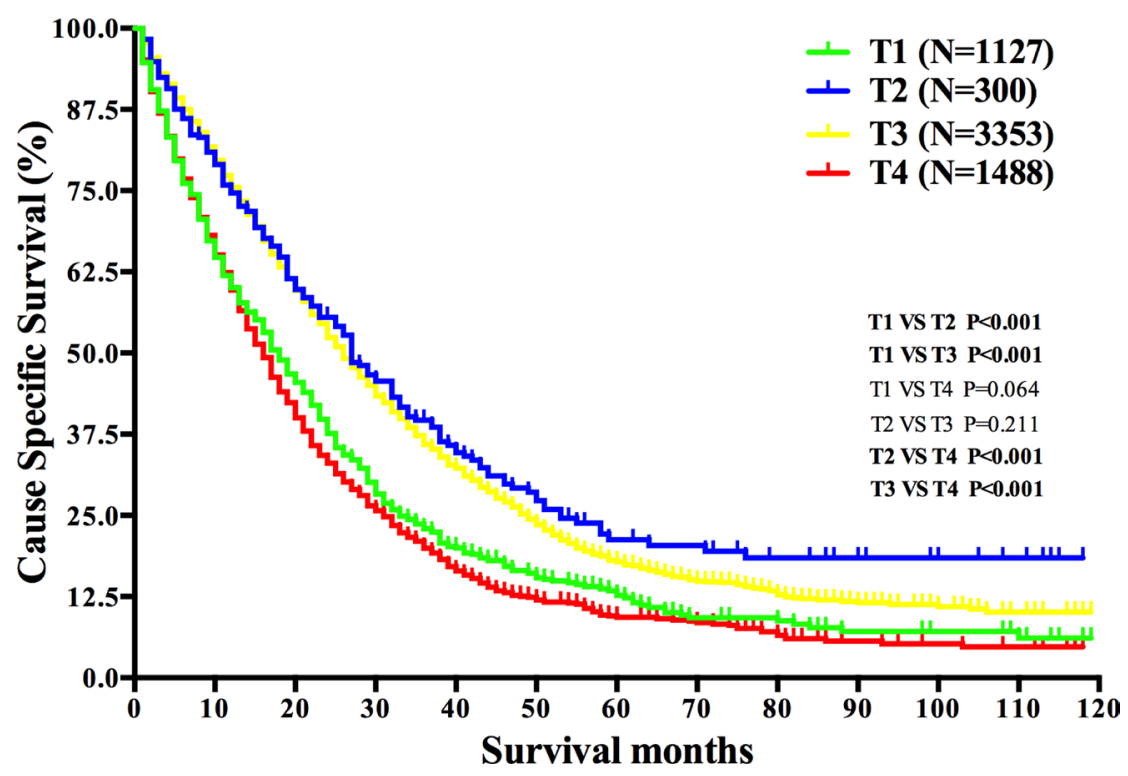

Figure 5: Survival analysis based on $\boldsymbol{T}$ stage in mRC. Abbreviations: $N$, number of patients; $T$, tumor. 
Table 3: Survival analysis of the influence of CEA level and $M$ stage on $\mathrm{mRC}$ patients when stratified by treatment combination in the SEER database

\begin{tabular}{|c|c|c|c|c|c|}
\hline \multirow{2}{*}{ Groups } & \multirow{2}{*}{ 2-year CSS } & \multicolumn{2}{|c|}{ Univariate analysis } & \multicolumn{2}{|c|}{ Multivariate analysis } \\
\hline & & Log $\operatorname{rank} \chi^{2}$ & $\boldsymbol{P}^{a}$ & HR (95\% CI) & $P^{b}$ \\
\hline \multicolumn{6}{|c|}{ SURG - RAD - } \\
\hline CEA & & 31.06 & $<0.001$ & & 0.017 \\
\hline Normal & $45.3 \%$ & & & $0.623(0.422-0.918)$ & \\
\hline Elevated & $25.6 \%$ & & & Reference & \\
\hline$M$ stage & & 0.96 & 0.328 & & 0.401 \\
\hline M1a & $40.9 \%$ & & & $0.874(0.638-1.196)$ & \\
\hline M1b & $35.2 \%$ & & & Reference & \\
\hline \multicolumn{6}{|c|}{ SURG - RAD + } \\
\hline CEA & & 4.976 & 0.016 & & 0.053 \\
\hline Normal & $36.8 \%$ & & & $0.794(0.589-0.991)$ & \\
\hline Elevated & $30.6 \%$ & & & Reference & \\
\hline$M$ stage & & 45.68 & $<0.001$ & & 0.006 \\
\hline M1a & $43.1 \%$ & & & $0.672(0.507-0.892)$ & \\
\hline M1b & $26.7 \%$ & & & Reference & \\
\hline \multicolumn{6}{|c|}{ SURG + RAD - } \\
\hline CEA & & 3.073 & 0.079 & & 0.037 \\
\hline Normal & $60.2 \%$ & & & $0.778(0.615-0.985)$ & \\
\hline Elevated & $50.3 \%$ & & & Reference & \\
\hline$M$ stage & & 13.69 & $<0.001$ & & 0.001 \\
\hline M1a & $63.2 \%$ & & & $0.648(0.503-0.835)$ & \\
\hline M1b & $46.9 \%$ & & & Reference & \\
\hline \multicolumn{6}{|c|}{ SURG + RAD + } \\
\hline CEA & & 29.15 & $<0.001$ & & $<0.001$ \\
\hline Normal & $73.7 \%$ & & & $0.596(0.473-0.750)$ & \\
\hline Elevated & $63.2 \%$ & & & Reference & \\
\hline$M$ stage & & 24.47 & $<0.001$ & & $<0.001$ \\
\hline M1a & $74.9 \%$ & & & $0.673(0.552-0.821)$ & \\
\hline M1b & $62.9 \%$ & & & Reference & \\
\hline
\end{tabular}

$P^{a}: P$ value for comparisons between groups by log-rank test.

$P^{b}: P$ value for comparisons between groups by multivariable Cox regression analysis adjusting for covariates.

Abbreviations: CEA, carcinoembryonic antigen; M, metastasis; $\mathrm{mRC}$, metastatic rectal cancer; CSS, cancer cause-specific survival; HR, hazard ratio; CI, confidence interval; SURG-, without surgery of the primary cancer; SURG+, with surgery of the primary cancer; RAD-, without radiation; RAD+, with radiation.

of patients with $\mathrm{T} 1$ or $\mathrm{T} 4$ stage in $\mathrm{mRC}$. For $\mathrm{mRC}$ with T1 stage, metastasis occurred despite the low $T$ stage, indicating the poor biological characteristics of primary cancer, which may lead to the short survival. And for mRC with T4 stage, the deep invasion depth showed the strong invasive and penetrating ability of primary cancer cell, which probably caused the poor survival. Other clinicopathological prognostic factors we identified in the analysis included tumor size, histological type and differentiate grade, which was in consistent with former studies [53-56].

Although this is a large population-based study focusing on $\mathrm{mRC}$ solely, several potential limitations inevitably exist for its inherent retrospective nature. Firstly, the study lacked the information of chemotherapy and molecule-targeted treatment for the SEER database lacks corresponding records originally, causing potential confounders in the analysis. However, the bias potentially applies to both surgery and non-surgery groups as well as to both radiation and non-radiation groups. Secondly, records in the SEER database don't include exact rectal cancer site, physical status, nutritional status, accompanied symptoms, as well as the specific metastatic status, which prevented us from making relevant analyses. Thirdly, records in the SEER database lack the evaluation of 
the resectability of metastases, making it impossible for us to distinguish between resectable metastases and unresectable metastases.

In conclusion, despite the potential limitations of this study, we found surgery of the primary cancer and radiotherapy could improve the CSS of $\mathrm{mRC}$ patients significantly, particularly when both treatments have been conducted. Hence we suggested the addition of surgery of the primary cancer and radiation into the treatment algorithms of mRC patients, especially when the patient is with a normal CEA level and/or with M1a stage. In addition, our results recommended clinicians to take CEA level, $M$ stage, $T$ stage, tumor size, differentiate grade, age and marital status into consideration when estimating the prognosis of $\mathrm{mRC}$ patients to help make the optimal treatment and follow-up plan.

\section{MATERIALS AND METHODS}

\section{Patient selection in the SEER database}

The SEER database covers about $26 \%$ of the population of the USA, contains 18 population-based cancer registries and provides the information on cancer statistics. We obtained the data of $\mathrm{mRC}$ from January 2004 to December 2013 from the SEER database by using SEER*Stat software (SEER*Stat version 8.3.2), for the record of the American Joint Committee on Cancer (AJCC) TNM stage in the database was not available until the year of 2004. Patients meeting the inclusion criteria were included in the analysis. The inclusion criteria: (1) the location of primary tumor: Rectum (the International Classification of Diseases for Oncology, 3rd Edition [ICD-O-3] site code: C20.9) ; (2) the number of primary tumor: only one primary cancer; (3) histological type: adenocarcinoma (ICD-O-3 histological type code: $8140 / 3$, $8210 / 3,8261 / 3,8263 / 3)$; mucinous adenocarcinoma $(8480 / 3)$ and signet ring cell carcinoma (8490/3); (4) AJCC TNM stage: stage IV; (5) pathologically confirmed diagnosis; (6) actively follow up. And patients who met the exclusion criteria were excluded from the analysis. The exclusion criteria: (1) diagnosed by death certificate or autopsy only; (2) without known survival months or cause-specific death classification.

\section{Data retrieved}

Records of the following demographic and clinicopathological variables were retrieved from the SEER database: gender, age at diagnosis, year of diagnosis, ethnicity, marital status; histological type, grade of differentiation, $T$ stage, $N$ stage, $M$ stage, tumor size, the status of site-specific factor 1 (CEA), surgery of the primary site, radiation, SEER cause-specific death classification and survival months.

The codes of surgery of the primary site for RC (1998-2013): 00 and 10-14, no surgery of the primary site;
20-28, local tumor excision; 30-40, partial proctectomy; 50 , total proctectomy; 60, total proctocolectomy; 70 , total proctectomy or proctocolectomy with an en bloc resection of other organs, including pelvic exenteration; 80 (proctectomy Not Otherwise Specified, NOS), unknown resection range; 90 (surgery NOS), was also considered as unknown resection range here.

\section{Statistical analysis}

The SPSS software (version 21.0) was used for statistical analysis. Chi-square test was used to test qualitative data. Student's $t$-test was used to compare quantitative data. The CSS of $\mathrm{mRC}$ was calculated from the date of diagnosis to the date of cancer specific death. Deaths attributed to $\mathrm{mRC}$ were treated as events and deaths from other reasons or survivals at the time of last followup were treated as censored observations. The CSS curves were plotted by Kaplan-Meier method and analyzed by log-rank test. Multivariable Cox regression analysis was used to find the risk factors for CSS. Two sided $P<0.05$ was considered to be statistically significant.

\section{Authors' contributions}

DT and WZ conceived of and designed the study. DT and WHL performed the analyses. WHL and FL prepared all the figures and tables. DT, WHL and FL wrote the main manuscript. All authors reviewed the manuscript.

\section{ACKNOWLEDGMENTS}

The authors appreciate the efforts of the staff of Surveillance, Epidemiology, and End Results (SEER) program and thank for the availability of the public access to SEER database.

\section{CONFLICTS OF INTEREST}

All authors declare no conflicts of interest.

\section{REFERENCES}

1. Siegel RL, Miller KD, Jemal A. Cancer statistics, 2015. CA Cancer J Clin. 2015; 65:5-29.

2. Ferlay J, Soerjomataram I, Dikshit R, Eser S, Mathers C, Rebelo M, Parkin DM, Forman D, Bray F. Cancer incidence and mortality worldwide: sources, methods and major patterns in GLOBOCAN 2012. Int J Cancer. 2015; 136:E359-386.

3. Chen W, Zheng R, Zeng H, Zhang S, He J. Annual report on status of cancer in China, 2011. Chin J Cancer Res. 2015; 27:2-12.

4. Lee WS, Yun SH, Chun HK, Lee WY, Yun HR, Kim J, Kim K, Shim YM. Pulmonary resection for metastases 
from colorectal cancer: prognostic factors and survival. Int J Colorectal Dis. 2007; 22:699-704.

5. Van Cutsem E, Nordlinger B, Adam R, Köhne CH, Pozzo C, Poston G, Ychou M, Rougier P; European Colorectal Metastases Treatment Group. Towards a pan-European consensus on the treatment of patients with colorectal liver metastases. Eur J Cancer. 2006; 42:2212-2221.

6. Yoo PS, Lopez-Soler RI, Longo WE, Cha CH. Liver resection for metastatic colorectal cancer in the age of neoadjuvant chemotherapy and bevacizumab. Clin Colorectal Cancer. 2006; 6:202-207.

7. Brenner H, Kloor M, Pox CP. Colorectal cancer. Lancet. 2014; 383:1490-1502.

8. Tamas K, Walenkamp AM, de Vries EG, van Vugt MA, Beets-Tan RG, van Etten B, de Groot DJ, Hospers GA. Rectal and colon cancer: Not just a different anatomic site. Cancer Treat Rev. 2015; 41:671-679.

9. Kalady MF, Sanchez JA, Manilich E, Hammel J, Casey G, Church JM. Divergent oncogenic changes influence survival differences between colon and rectal adenocarcinomas. Dis Colon Rectum. 2009; 52:1039-1045.

10. Fang YJ, Wu XJ, Zhao Q, Li LR, Lu ZH, Ding PR, Zhang RX, Kong LH, Wang FL, Lin JZ, Chen G, Pan ZZ, Wan DS. Hospital-based colorectal cancer survival trend of different tumor locations from 1960 s to 2000 s. PLoS One. 2013; 8:e73528.

11. Goldberg RM, Sargent DJ, Morton RF, Fuchs CS, Ramanathan RK, Williamson SK, Findlay BP, Pitot HC, Alberts SR. A randomized controlled trial of fluorouracil plus leucovorin, irinotecan, and oxaliplatin combinations in patients with previously untreated metastatic colorectal cancer. J Clin Oncol. 2004; 22:23-30.

12. Fuchs CS, Marshall J, Mitchell E, Wierzbicki R, Ganju V, Jeffery M, Schulz J, Richards D, Soufi-Mahjoubi R, Wang B, Barrueco J. Randomized, controlled trial of irinotecan plus infusional, bolus, or oral fluoropyrimidines in first-line treatment of metastatic colorectal cancer: results from the BICC-C Study. J Clin Oncol. 2007; 25:4779-4786.

13. Poon MA, O'Connell MJ, Moertel CG, Wieand HS, Cullinan SA, Everson LK, Krook JE, Mailliard JA, Laurie JA, Tschetter LK, Wiesenfeld M. Biochemical modulation of fluorouracil: evidence of significant improvement of survival and quality of life in patients with advanced colorectal carcinoma. J Clin Oncol. 1989; 7:1407-1418.

14. Hurwitz H, Fehrenbacher L, Novotny W, Cartwright T, Hainsworth J, Heim W, Berlin J, Baron A, Griffing S, Holmgren E, Ferrara N, Fyfe G, Rogers B, et al. Bevacizumab plus irinotecan, fluorouracil, and leucovorin for metastatic colorectal cancer. N Engl J Med. 2004; 350:2335-2342.

15. Van Cutsem E, Köhne CH, Hitre E, Zaluski J, Chang Chien CR, Makhson A, D'Haens G, Pintér T, Lim R, Bodoky G, Roh JK, Folprecht G, Ruff P, et al. Cetuximab and chemotherapy as initial treatment for metastatic colorectal cancer. N Engl J Med. 2009; 360:1408-1417.

16. Anwar S, Peter MB, Dent J, Scott NA. Palliative excisional surgery for primary colorectal cancer in patients with incurable metastatic disease. Is there a survival benefit? A systematic review. Colorectal Dis. 2012; 14:920-930.

17. Tan TH, Kosmider S, Yip D, Gibbs P. Clinical experience of selective internal radiation therapy in combination with systemic chemotherapy as first-line therapy in patients with unresectable hepatic metastases from colorectal cancer. J Clin Oncol. 2008; 26:15080.

18. Liu KT, Wan JF, Yu GH, Bei YP, Chen X, Lu MZ. The recommended treatment strategy for locally advanced gastric cancer in elderly patients aged 75 years and older: a Surveillance, Epidemiology, and End Results database analysis. J Cancer Res Clin Oncol. 2017; 143:313-320.

19. Wan JF, Zhu J, Li GC, Sun WJ, Zhang Z. Implications for determining the optimal treatment for locally advanced rectal cancer in elderly patients aged 75 years and older. Oncotarget. 2015; 6:30377-30383. https://doi.org/10.18632/ oncotarget.4599.

20. Yang D, Lenz C, Togawa K, Lurje G, Pohl A, Manegold PC, Ning Y, Groshen SG, Groshen HJ. Age and ethnicity predict overall survival in patients with metastatic gastric cancer. J Clin Oncol. 2008; 26:15500.

21. Hendifar AE, Lurje G, Lenz F, Pohl A, Manegold PC, Togawa K, Husain H, Lenz HJ, Yang D. Sex, age, and ethnicity are associated with survival in metastatic colorectal cancer. J Clin Oncol. 2008; 26:4015.

22. Jiang Z, Wang X, Tan X, Fan Z. Effect of Age on Survival Outcome in Operated and Non-Operated Patients with Colon Cancer: A Population-Based Study. PLoS One. 2016; 11:e0147383.

23. Abe S, Kawai K, Ishihara S, Nozawa $H$, Hata $K$, Kiyomatsu T, Tanaka T, Watanabe T. Prognostic impact of carcinoembryonic antigen and carbohydrate antigen 19-9 in stage IV colorectal cancer patients after R0 resection. J Surg Res. 2016; 205:384-392.

24. Fang JY, Dong HL, Sang XJ, Xie B, Wu KS, Du PL, Xu ZX, Jia XY, Lin K. Colorectal Cancer Mortality Characteristics and Predictions in China, 1991-2011. Asian Pac J Cancer Prev. 2015; 16:7991-7995.

25. Nitzkorski JR, Willis AI, Nick D, Zhu F, Farma JM, Sigurdson ER. Association of race and socioeconomic status and outcomes of patients with rectal cancer. Ann Surg Oncol. 2013; 20:1142-1147.

26. Berger MD, Yang D, Sunakawa Y, Zhang W, Ning Y, Matsusaka S, Okazaki S, Miyamoto Y, Suenaga M, Schirripa M, Lenz AM, Bohanes P, Barzi A, et al. Impact of sex, age, and ethnicity/race on the survival of patients with rectal cancer in the United States from 1988 to 2012. Oncotarget. 2016; 7:53668-53678. https://doi.org/10.18632/oncotarget.10696.

27. Li Q, Gan L, Liang L, Li X, Cai S. The influence of marital status on stage at diagnosis and survival of patients with 
colorectal cancer. Oncotarget. 2015; 6:7339-7347. https:// doi.org/10.18632/oncotarget.3129.

28. Tarantino I, Warschkow R, Worni M, Cerny T, Ulrich A, Schmied BM, Güller U. Prognostic Relevance of Palliative Primary Tumor Removal in 37,793 Metastatic Colorectal Cancer Patients: A Population-Based, Propensity ScoreAdjusted Trend Analysis. Ann Surg. 2015; 262:112-120.

29. Crane CH, Janjan NA, Abbruzzese JL, Curley S, Vauthey J, Sawaf HB, Dubrow R, Allen P, Ellis LM, Hoff P, Wolff RA, Lenzi R, Brown TD, et al. Effective pelvic symptom control using initial chemoradiation without colostomy in metastatic rectal cancer. Int J Radiat Oncol Biol Phys. 2001; 49:107-116.

30. Johnson WR, McDermott FT, Pihl E, Milne BJ, Price AB, Hughes ES. Palliative operative management in rectal carcinoma. Dis Colon Rectum. 1981; 24:606-609.

31. Hosseinali Khani M, Pahlman L, Smedh K. Treatment strategies for patients with stage IV rectal cancer: a report from the Swedish Rectal Cancer Registry. Eur J Cancer. 2012; 48:1616-1623.

32. Michel P, Roque I, Di Fiore F, Langlois S, Scotte M, Tenière $\mathrm{P}$, Paillot $\mathrm{B}$. Colorectal cancer with non-resectable synchronous metastases: should the primary tumor be resected? Gastroenterol Clin Biol. 2004; 28:434-437.

33. Benoist S, Pautrat K, Mitry E, Rougier P, Penna C, Nordlinger B. Treatment strategy for patients with colorectal cancer and synchronous irresectable liver metastases. Br J Surg. 2005; 92:1155-1160.

34. Sigurdsson HK, Kørner H, Dahl O, Skarstein A, Søreide JA, Norwegian Rectal Cancer Group. Palliative surgery for rectal cancer in a national cohort. Colorectal Dis. 2008; 10:336-343.

35. Rosen SA, Buell JF, Yoshida A, Kazsuba S, Hurst R, Michelassi F, Millis JM, Posner MC. Initial presentation with stage IV colorectal cancer: how aggressive should we be? Arch Surg. 2000; 135:530-534; discussion 534-535.

36. Stelzner S, Hellmich G, Koch R, Ludwig K. Factors predicting survival in stage IV colorectal carcinoma patients after palliative treatment: a multivariate analysis. J Surg Oncol. 2005; 89:211-217.

37. Chang CY, Kim HC, Park YS, Park JO, Choi DH, Park HC, Cho YB, Yun SH, Lee WY, Chun HK. The effect of postoperative pelvic irradiation after complete resection of metastatic rectal cancer. J Surg Oncol. 2012; 105:244-248.

38. Kim JW, Kim YB, Kim NK, Min BS, Shin SJ, Ahn JB, Koom WS, Seong J, Keum KC. The role of adjuvant pelvic radiotherapy in rectal cancer with synchronous liver metastasis: a retrospective study. Radiat Oncol. 2010; 5:75.

39. Tsai HL, Huang CW, Chen CW, Yeh YS, Ma CJ, Wang JY. Survival in Resected Stage II Colorectal Cancer Is Dependent on Tumor Depth, Vascular Invasion, Postoperative CEA Level, and The Number of Examined Lymph Nodes. World J Surg. 2016; 40:1002-1009.
40. Huh JW, Lee WY, Park YA, Cho YB, Yun SH, Kim HC, Chun HK. Prognostic factors associated with primary cancer in curatively resected stage IV colorectal cancer. J Cancer Res Clin Oncol. 2014; 140:435-441.

41. Araujo RL, Gönen M, Allen P, DeMatteo R, Kingham P, Jarnagin W, D'Angelica M, Fong Y. Positive postoperative CEA is a strong predictor of recurrence for patients after resection for colorectal liver metastases. Ann Surg Oncol. 2015; 22:3087-3093.

42. Kim CH, Huh JW, Kim HJ, Lim SW, Song SY, Kim HR, $\mathrm{Na}$ KJ, Kim YJ. Factors influencing oncological outcomes in patients who develop pulmonary metastases after curative resection of colorectal cancer. Dis Colon Rectum. 2012; 55:459-464.

43. Steele SR, Chang GJ, Hendren S, Weiser M, Irani J, Buie WD, Rafferty JF. Clinical Practice Guidelines Committee of the American Society of Colon and Rectal Surgeons. Practice Guideline for the Surveillance of Patients After Curative Treatment of Colon and Rectal Cancer. Dis Colon Rectum. 2015; 58:713-725.

44. Stillwell AP, Ho YH, Veitch C. Systematic review of prognostic factors related to overall survival in patients with stage IV colorectal cancer and unresectable metastases. World J Surg. 2011; 35:684-692.

45. Aggarwal C, Meropol NJ, Punt CJ, Iannotti N, Saidman BH, Sabbath KD, Gabrail NY, Picus J, Morse MA, Mitchell E, Miller MC, Cohen SJ. Relationship among circulating tumor cells, CEA and overall survival in patients with metastatic colorectal cancer. Ann Oncol. 2013; 24:420-428.

46. Tarantino I, Warschkow R, Worni M, Merati-Kashani K, Köberle D, Schmied BM, Müller SA, Steffen T, Cerny T, Güller U. Elevated preoperative CEA is associated with worse survival in stage I-III rectal cancer patients. Br J Cancer. 2012; 107:266-274.

47. Giessen C, Nagel D, Glas M, Spelsberg F, Lau-Werner U, Modest DP, Michl M, Heinemann V, Stieber P, Schulz C. Evaluation of preoperative serum markers for individual patient prognosis in stage I-III rectal cancer. Tumour Biol. 2014; 35:10237-10248.

48. Armstrong D, Raissouni S, Price Hiller J, Mercer J, Powell E, MacLean A, Jiang M, Doll C, Goodwin R, Batuyong E, Zhou K, Monzon JG, Tang PA, et al. Predictors of Pathologic Complete Response After Neoadjuvant Treatment for Rectal Cancer: A Multicenter Study. Clin Colorectal Cancer. 2015; 14:291-295.

49. Kobayashi H, Kotake K, Sugihara K. Prognostic scoring system for stage IV colorectal cancer: is the AJCC subclassification of stage IV colorectal cancer appropriate? Int J Clin Oncol. 2013; 18:696-703.

50. Franko J, Shi Q, Goldman CD, Pockaj BA, Nelson GD, Goldberg RM, Pitot HC, Grothey A, Alberts SR, Sargent DJ. Treatment of colorectal peritoneal carcinomatosis with systemic chemotherapy: a pooled analysis of north central 
cancer treatment group phase III trials N9741 and N9841. J Clin Oncol. 2012; 30:263-267.

51. Kozak KR, Moody JS. The impact of T and N stage on longterm survival of rectal cancer patients in the community. J Surg Oncol. 2008; 98:161-166.

52. Gunderson LL, Sargent DJ, Tepper JE, Wolmark N, O'Connell MJ, Begovic M, Allmer C, Colangelo L, Smalley SR, Haller DG, Martenson JA, Mayer RJ, Rich TA, et al. Impact of $\mathrm{T}$ and $\mathrm{N}$ stage and treatment on survival and relapse in adjuvant rectal cancer: a pooled analysis. J Clin Oncol. 2004; 22:1785-1796.

53. Poritz LS, Sehgal R, Hartnett K, Berg A, Koltun WA. Tumor volume and percent positive lymph nodes as a predictor of 5-year survival in colorectal cancer. Surgery. 2011; 150:649-655.
54. Nozoe T, Anai H, Nasu S, Sugimachi K. Clinicopathological characteristics of mucinous carcinoma of the colon and rectum. J Surg Oncol. 2000; 75:103-107.

55. Heys SD, Sherif A, Bagley JS, Brittenden J, Smart C, Eremin O. Prognostic factors and survival of patients aged less than 45 years with colorectal cancer. Br J Surg. 1994; 81:685-688.

56. Stahle E, Glimelius B, Bergstrom R, Pahlman L. Preoperative clinical and pathological variables in prognostic evaluation of patients with rectal cancer. A prospective study of 327 consecutive patients. Acta Chir Scand. 1988; 154:231-239. 